\title{
FINITE ELEMENT ANALYSIS OF NOTCHED BAR SKELETAL POINT STRESSES AND DIMENSION CHANGES DUE TO CREEP
}

\author{
G.A.Webster and K.M Nikbin \\ Department of Mechanical Engineering \\ Imperial College \\ London SW7 2BX
}

\begin{abstract}
In this investigation finite element calculations have been performed to obtain the creep stress distributions generated in circumferentially notched bar test-pieces. They have also been made to determine the relation between axial extension and notch throat diameter changes. It has been found that an approximate skeletal point can be identified where the stress state is insensitive to the power law stress dependence of creep. Consistent trends in skeletal point stress ratios to those given in an existing Code of Practice for notch bar creep testing have been obtained. Nevertheless up-dated values, particularly for sharp notches, are proposed and these have now been inserted into a new version of the Code of Practice. In contrast the link between extension and notch throat diameter changes has been found to depend on the creep stress index as well as the notch geometry. It is anticipated that the analysis can be used to establish the multi-axial creep stress deformation and rupture behaviour of materials.
\end{abstract}

\section{Nomenclature}

$a, b, c \quad$ Coefficients in equations to determine skeletal stress ratios

A Coefficient in creep law

$d_{n o} \quad$ Initial diameter of notch throat of test-piece

$D \quad$ Diameter of parallel portion of gauge section of test-piece

E $\quad$ Elastic modulus

$L_{e} \quad$ Extensometer gauge length

$n \quad$ Stress dependence in creep law

$r \quad$ Radial coordinate at notch plane 


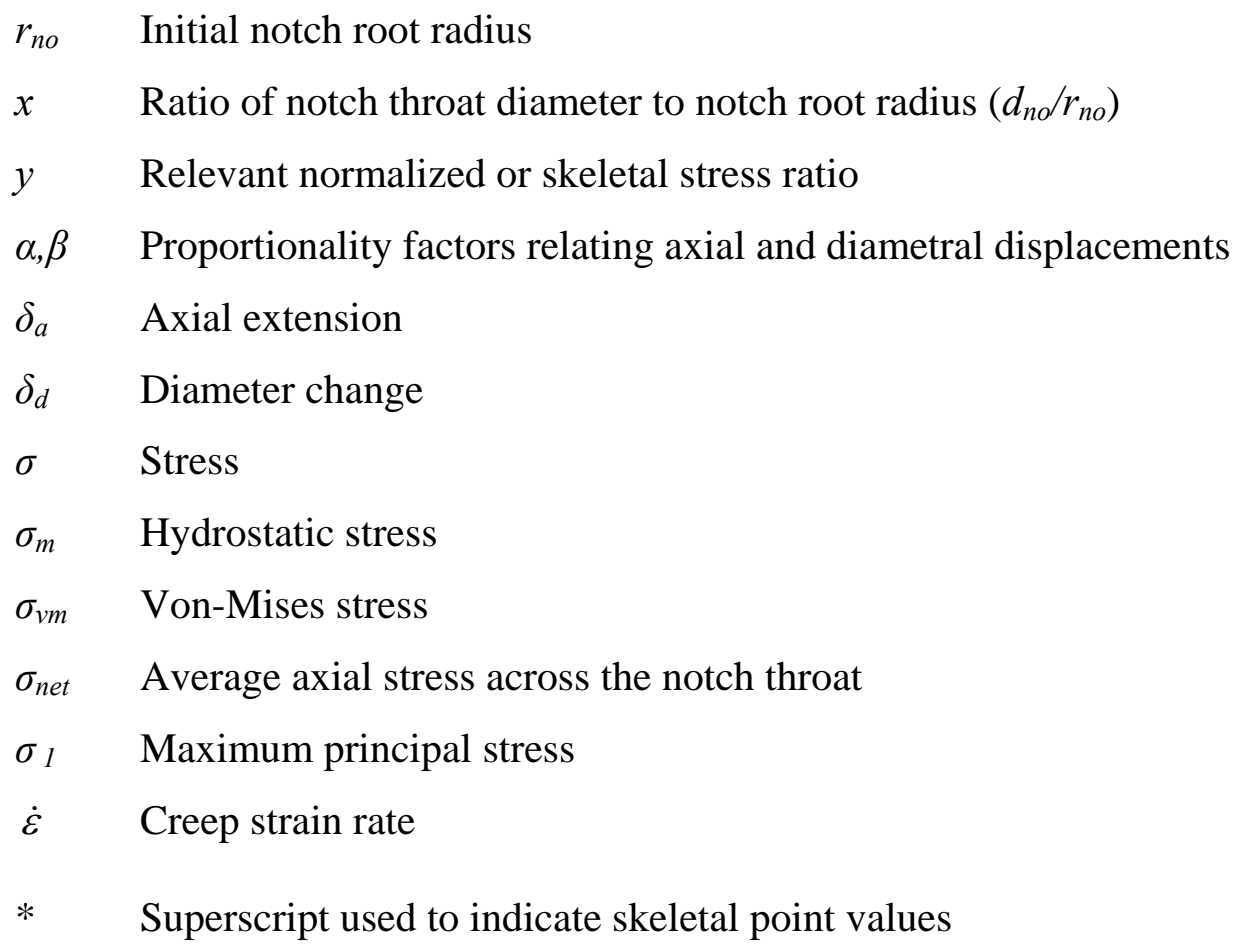

\section{Introduction}

Circumferentially notched bars loaded in tension have been used for many years to examine the notch sensitivity of materials to creep failure. A code of practice was issued initially in 1991 as an NPL publication (1) and subsequently externally in 1992 (2) for carrying out these tests and for interpreting the experimental results. Although performance of the tests is straightforward, interpretation of the data requires the use of computer analysis. The computer analysis in the code was based on finite element calculations that were made in the 1980's $(3,4)$ when computing power was much less than is now available. This investigation was undertaken to update these calculations for a re-issue of the code of practice and to establish a relationship between axial displacement and notch throat diameter changes.

\section{Calculations}

The geometry of notched bar specimens examined corresponded with that recommended in the revised Code of Practice (5) and shown in Fig. 1. Each bar had a double notch with $D / d_{n o}=\sqrt{2}$ and calculations were made for $d_{n o} / 2 r_{n o}=5,15$ and 25 to cover the range of interest in the code. The actual values chosen for these parameters, together with the distance $L_{e}$ between extensometer ridges are given in Table 1 . The calculations were carried out assuming elastic behaviour on loading and a Norton power law creep response with

$$
\dot{\varepsilon}=A \sigma^{n}
$$


In the calculations, the elastic modulus $E$ was taken as $200 \mathrm{GPa}$ and $A$ was chosen to give a creep rate $\dot{\varepsilon}$ of $10^{-5} / h$ at a stress $\sigma$ of $200 \mathrm{MPa}$ from a given $n$ value. A net section stress of $200 \mathrm{MPa}$ across the notch throat was applied to all the geometries and calculations were made for $n=1,3,5,7,10$ and 20 .

The ABAQUS version 5.8 finite element package was used to make the calculations. From symmetry only one half of the geometry was modelled. An illustration of the type of finite element mesh in the local notch region that was employed is shown in Fig. 2. Checks were made to ensure that it was sufficiently fine. The calculations were performed until stress redistribution in the notch throat region was complete and steady state conditions had been achieved. In all cases the Von-Mises $\sigma_{v m}$, maximum principal $\sigma_{l}$ and the hydrostatic $\sigma_{m}$ stresses were calculated as a function of radius across the minimum section of the notch throat for each value of the creep index $n$ versus the notch length $a(\mathrm{~mm})$; as illustrated in Figs. 3-5 for $d_{n o} / 2 r_{n o}=5$. For each geometry it was found that an approximate skeletal point existed where the stress was found to be almost constant, irrespective of the value of $n$, for $n>3$. The radial position of the skeletal point is identified as $r^{*}$ in the figures. Although this radius was not exactly the same for a given geometry for each stress, it was found possible to define a suitably small skeletal zone in which the stresses could be identified. The ratios of these stresses to the net section stress are presented in Fig. 6. Also included in this figure are values which have been produced by other calculations performed at Imperial College, British Energy and Alstom for other notch geometries. Figure 7 shows the corresponding skeletal stress ratios $\sigma_{m}^{*} / \sigma_{v m}^{*}$ and $\sigma_{1}^{*} / \sigma_{v m}^{*}$ for use in establishing the multiaxial deformation and fracture behaviour of materials. It has been found that a function

$$
y=c \exp \left(\frac{a}{1+b x}\right) \quad \text { or } \quad y=\exp \left(\frac{a x}{1+b x}\right)
$$

can be fitted to each of the data sets in Figs. 6 and 7 where the values of $a, b$ and $c$ are given in Table 2. In these expressions $y$ represents the relevant normalized or skeletal stress ratios and $x$ the ratio of the notch throat diameter to notch root radius $d_{n o} / r_{n o}$. Tables 3 and 4 list the normalized skeletal stresses and the skeletal stress ratios derived from eq (2).

Calculations have also been made to link axial displacement measurements across the extensometer ridges with notch throat diameter changes. An example is shown in Fig. 8. Similar results were obtained for the other geometries. It has been found that once steady 
state conditions have been reached, after an axial extension of about $0.1 \mathrm{~mm}$, a linear relationship exists between the length and diameter changes so that

$$
\delta_{a}=-\alpha \delta_{d}
$$

where $\alpha$ is the proportionality factor between the axial extension $\delta_{a}$ and diameter change $\delta_{d}$. Values of $\alpha$ for each notch geometry and $n$ are given in Table 5. These are plotted in Fig. 9 where it can be seen that $\alpha$ can be expressed as

$$
\alpha=\beta n^{-0.51}
$$

where for $d_{n o} / 2 r_{n o}=5,15$ and 25, $\beta=12.3,15$ and 16, respectively.

\section{Discussion}

A re-analysis has been performed by finite element methods of the stress distributions generated by creep across the notch throat region of notched bar test-pieces. Once a steady state stress distribution has been achieved, it has been found that a skeletal point can be identified where the stress state is approximately independent of the stress index $n$ of creep. Calculations have been made to determine the Von-Mises $\sigma_{v m}^{*}$, maximum principal $\sigma_{1}^{*}$, and mean $\sigma_{m}^{*}$ stresses at this point for insertion into models for establishing the multiaxial creep stress rupture behaviour of materials (6-9). An attraction of the skeletal point concept is that it enables the stress state generated in a notch throat to be identified without a detailed knowledge of the creep properties of a material being available. It is argued that the stress state at the skeletal point can be used to describe the overall creep behaviour of the notched bar test-pieces. In order to establish the multiaxial creep stress rupture criterion of a material, it is necessary to carry out experiments on different notch shapes to cover a range of skeletal point stress states. If the stress state in a particular component only is to be replicated, it is only necessary to test the notch shape which most closely matches the stress state in the component.

The same trends in skeletal point stresses have been identified as were obtained in the previous Code of Practice $(1,2)$. However, it has been found necessary to up-date some of the values, particularly for sharp notches. These have now been incorporated in the new version of the Code of Practice (5). 
In addition calculations have been made to relate gauge length extension to notch throat diameter changes so that if measurements of one are made in an experiment the other can be calculated. In most instances extensions are measured but diameter changes are needed for establishing creep deformation local to a notch where the stress state is most intense. Although skeletal point stresses are insensitive to the creep stress index $n$ it has been found that the relationship between axial extension and diameter changes is dependent on $n$. It also depends on notch shape. Expressions, eqns. (3) and (4), have been developed for determining this relation. It should be noted that the $\alpha$ values obtained in eqns ( 3 and 4 ) are derived assuming eqn. (1). For situations where significant tertiary is involved this relationship may be different.

\section{Conclusions}

Finite element calculations have been performed to update the analysis in the Code of Practice $(1,2)$ for testing notched bars. It has been found possible to identify an appropriate skeletal zone. The broad trends in the stress ratios in the code have been confirmed although some changes in their values are recommended for inclusion in a new version of the Code (5).

Calculations have been made to link axial extension and diameter changes. These have been found to depend on notch geometry and the creep stress index. It is anticipated that the results can be applied to interpret the multiaxial creep stress deformation and fracture behaviour of notched bars.

\section{Acknowledgements}

The authors would like to thank the National Physical Laboratory for financial support for the investigation. They would also like to acknowledge the contributions of S.R Holdsworth, I.J. Perrin, B. Thompson (Alston Power), S.J Kiff, K.L Moore, M. O’Donnell, M.W Spindler (Bristol Energy Generation), F. Biglari (Amir Kabir University), A. Bettinson, R.W Dempers, R.P Skelton (Imperial College) and M.S Loveday (National Physical Laboratory).

\section{References}

1. WEBSTER, G.A., APLIN, P.F., CANE, B.J., DYSON, B.F. and LOVEDAY, M.S., 'A code of practice for notched bar creep rupture testing: procedures and interpretation of data for design', ISBN-0-946754-13-6. Published by NPL, 1991. 
2. WEBSTER, G.A, APLIN, P.F, CANE, B.J, DYSON, B.F and LOVEDAY, M.S, 'A code of practice for 'notched bar creep rupture testing: procedures and interpretation of data for design', in Harmonisation of Testing Practice for High Temperature Materials' (Eds M.S. Loveday and T.B. Gibbons), Elsevier Applied Science, London, 1992, 295-330.

3. AL-FADDAGH, K.D, FENNER, R.T, \& WEBSTER, G.A, 'Steady state stress distributions in circumferentially notched bars subjected to creep', J. Strain Anal. 17, 123, 1982.

4. HAYHURST, D.R \& WEBSTER, G.A, 'An overview on studies of stress state effects during creep of circumferentially notched bars', in Techniques for Multiaxial Creep Testing, (Eds. D.J. Gooch and I.M. How), Elsevier Applied Science, London, 1986, 137-178.

5. WEBSTER G.A, HOLDSWORTH S.R, LOVEDAY M.S, PERRIN I.J \& PURPER H. A 'Code of Practice for conducting notched bar creep rupture tests and for interpreting the data' Issue 2a, To be published in this issue.

6. RICE, JR \& TRACEY, D.M 'On the ductile enlargement of voids in triaxial stress fields.' J. Mech. Phys. Solids. 17, 201-217, 1969

7. HAYHURST, D.R 'Creep rupture under multiaxial states of stress' J. Mech. Phys. Solids. 20, 381-390, 1972

8. COCKS, A.C.F \& ASHBY, M.F 'Intergranuler fracture during power law creep under multiaxial stress’ Met. Sci. 14 , 395-402, 1980

9. SPINDLER, M.W, HALES, R. \& SKELTON, R.P 'The multiaxial creep ductility of an exservice type 316 H Stainless Steel', in Creep and Fracture in Engineering Materials and Structures (Ed J.D Parker), Inst. Mat. London, 679-688, 2001 
Table 1: Dimensions of specimens examined.

\begin{tabular}{|lc|}
\hline$d_{n o} / 2=2.82 \mathrm{~mm}$ \\
$D / 2=4.00 \mathrm{~mm}$ \\
$L_{e} / 2=3.06 \mathrm{~mm}$ \\
\hline \multicolumn{2}{|l|}{$d_{n o} / 2 r_{n o} \quad r_{n o}$} \\
5 & 0.564 \\
15 & 0.19 \\
25 & 0.113 \\
\hline
\end{tabular}

Table 2: The constants derived for the curve fits of Figures 6 and 7 using Eqn. (2)

\begin{tabular}{|c|c|c|c|}
\hline Stress Ratio & $\boldsymbol{a}$ & $\boldsymbol{b}$ & $\boldsymbol{c}$ \\
\hline$\sigma_{v m}^{*} / \sigma_{n e t}$ & -0.169 & 0.310 & - \\
\hline$\sigma_{m}^{*} / \sigma_{n e t}$ & -1.074 & 0.259 & 0.987 \\
\hline$\sigma_{1}^{*} / \sigma_{n e t}$ & 0.020 & 0.049 & - \\
\hline$\sigma_{m}^{*} / \sigma_{v m}^{*}$ & -1.633 & 0.299 & 1.667 \\
\hline$\sigma_{1}^{*} / \sigma_{v m}^{*}$ & 0.153 & 0.172 & \\
\hline
\end{tabular}

Table 3: Best-fit values of the normalized skeletal stresses derived from the fitted lines in Fig.6 using Eqn. (2) and the constants in Table 2

\begin{tabular}{|c|c|c|c|}
\hline $\begin{array}{c}\text { Notch Acuity } \\
\text { Ratio }\end{array}$ & \multicolumn{3}{|l|}{ Normalised Stresses } \\
\cline { 2 - 4 }$\frac{d_{n o}}{r_{n o}}$ & $\frac{\sigma_{v m}^{*}}{\sigma_{n e t}}$ & $\frac{\sigma_{m}^{*}}{\sigma_{n e t}}$ & $\frac{\sigma_{1}^{*}}{\sigma_{n e t}}$ \\
\hline 1 & 0.88 & 0.42 & 1.02 \\
\hline 2 & 0.81 & 0.49 & 1.04 \\
\hline 3 & 0.77 & 0.54 & 1.05 \\
\hline 4.82 & 0.72 & 0.61 & 1.08 \\
\hline 10 & 0.66 & 0.73 & 1.14 \\
\hline 20 & 0.63 & 0.83 & 1.22 \\
\hline 30 & 0.61 & 0.87 & 1.28 \\
\hline 35 & 0.61 & 0.89 & 1.29 \\
\hline 50 & 0.58 & 0.91 & 1.34 \\
\hline
\end{tabular}


Table 4: Best fit values of the skeletal stress ratios derived from the fitted lines in Fig.7 using Eqn. (2) and the constants in Table 2

\begin{tabular}{|c|c|c|}
\hline $\begin{array}{c}\text { Notch Acuity } \\
\text { Ratio }\end{array}$ & \multicolumn{2}{|l|}{ Stress Ratios } \\
\cline { 2 - 3 }$\frac{d_{n o}}{r_{n o}}$ & $\frac{\sigma_{m}^{*}}{\sigma_{v m}^{*}}$ & $\frac{\sigma_{1}^{*}}{\sigma_{v m}^{*}}$ \\
\hline 1 & 0.47 & 1.14 \\
\hline 2 & 0.60 & 1.26 \\
\hline 3 & 0.71 & 1.35 \\
\hline 4.82 & 0.86 & 1.50 \\
\hline 10 & 1.11 & 1.76 \\
\hline 20 & 1.32 & 1.99 \\
\hline 30 & 1.42 & 2.11 \\
\hline 35 & 1.45 & 2.14 \\
\hline 50 & 1.51 & 2.22 \\
\hline
\end{tabular}

TABLE 5: Ratio of axial extension to diametral contraction for each notch shape.

\begin{tabular}{|c|c|c|c|}
\hline$n$ & \multicolumn{3}{|c|}{$\alpha$} \\
\hline & $d_{n o} / 2 r_{n o}=5$ & $d_{n o} / 2 r_{n o}=15$ & $d_{n o} / 2 r_{n o}=25$ \\
\hline 20 & 2.66 & 3.28 & 3.52 \\
\hline 10 & 3.76 & 4.34 & 4.99 \\
\hline 7 & 4.39 & 5.54 & 5.91 \\
\hline 5 & 5.34 & 6.82 & 7.2 \\
\hline 3 & 7.15 & 9.25 & 9.6 \\
\hline 1 & 11.5 & 14.68 & 15.43 \\
\hline
\end{tabular}




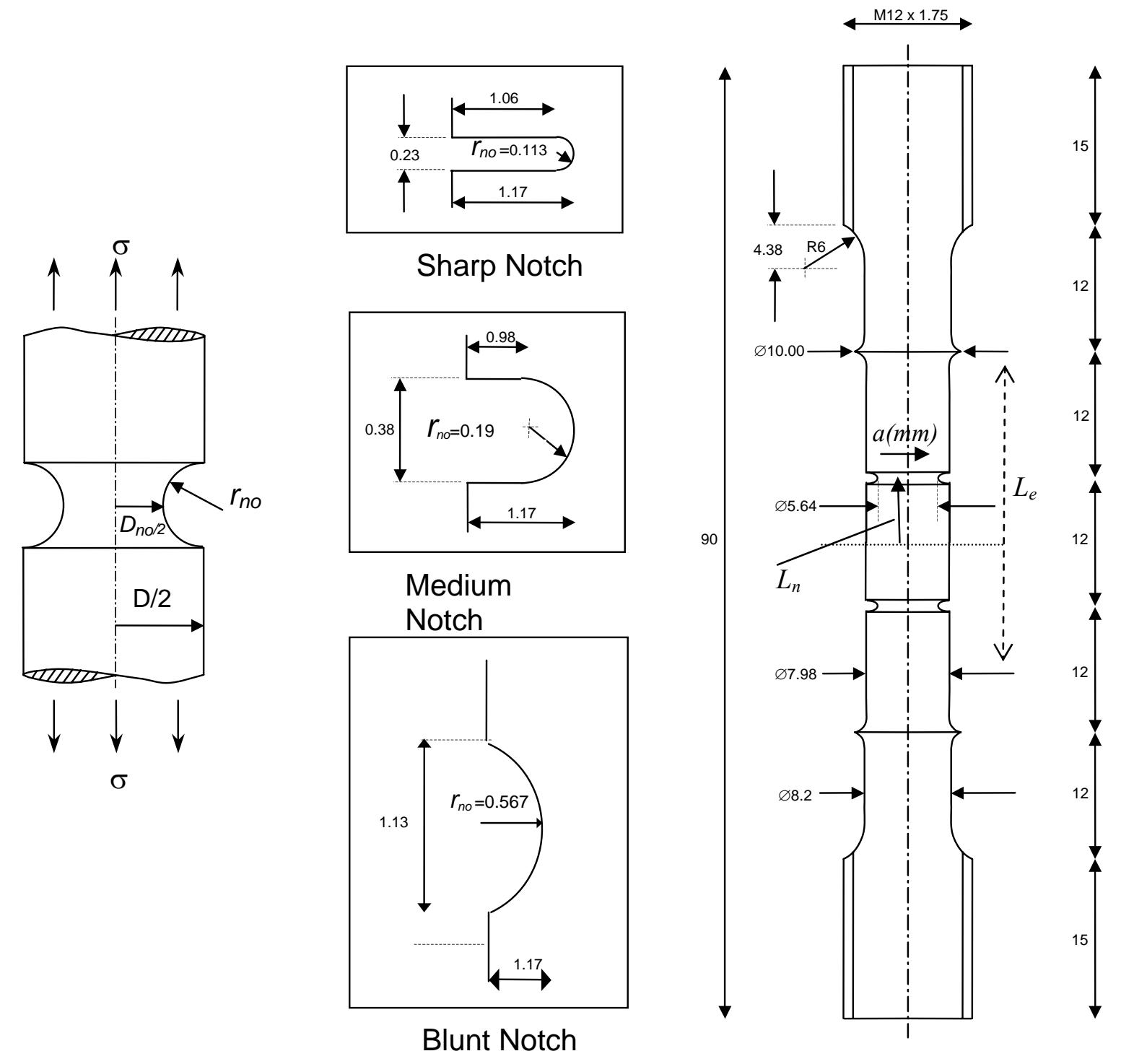

Figure 1: Drawing of the axisymmetrically notched bars showing the dimensions for a sharp, medium and a blunt notch. (sizes in $(\mathrm{mm})$ ) 


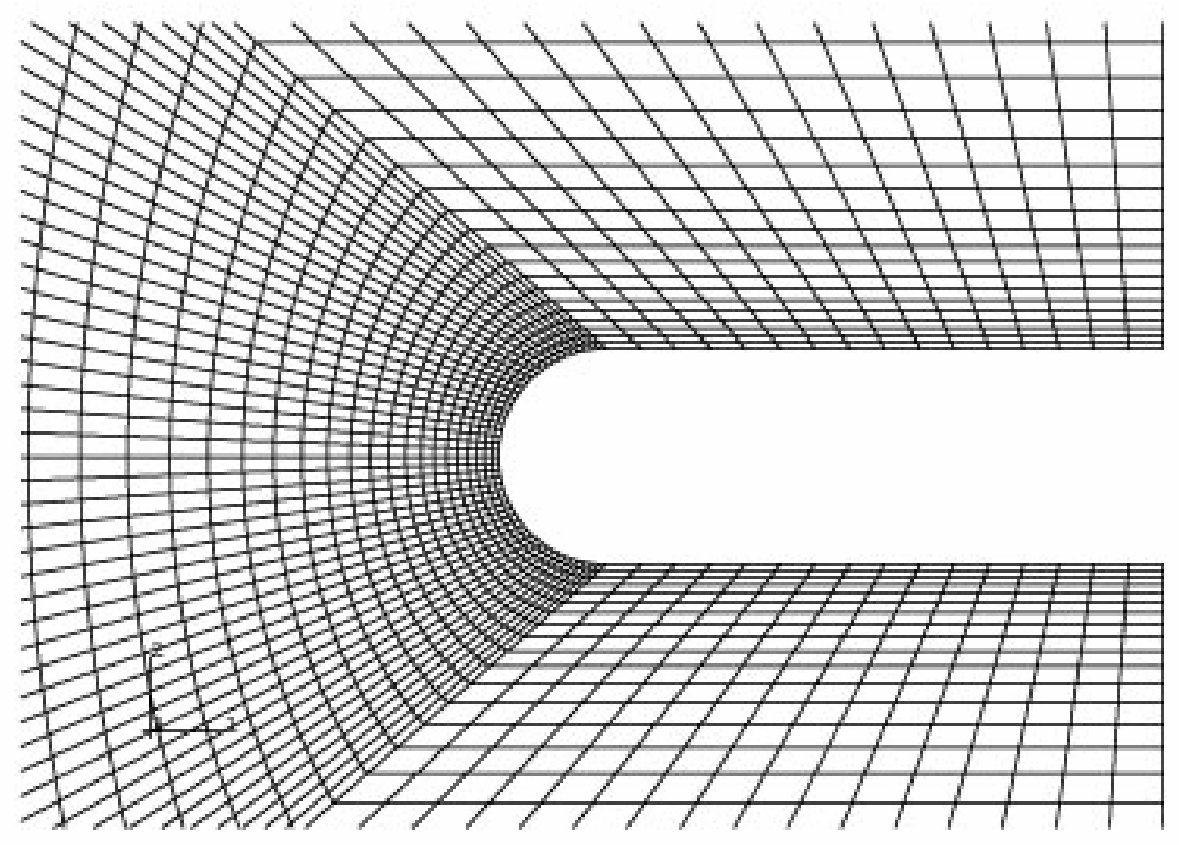

Figure 2: An illustration, for the sharp notch profile, of the type of finite element mesh refinement employed local to the notch region.

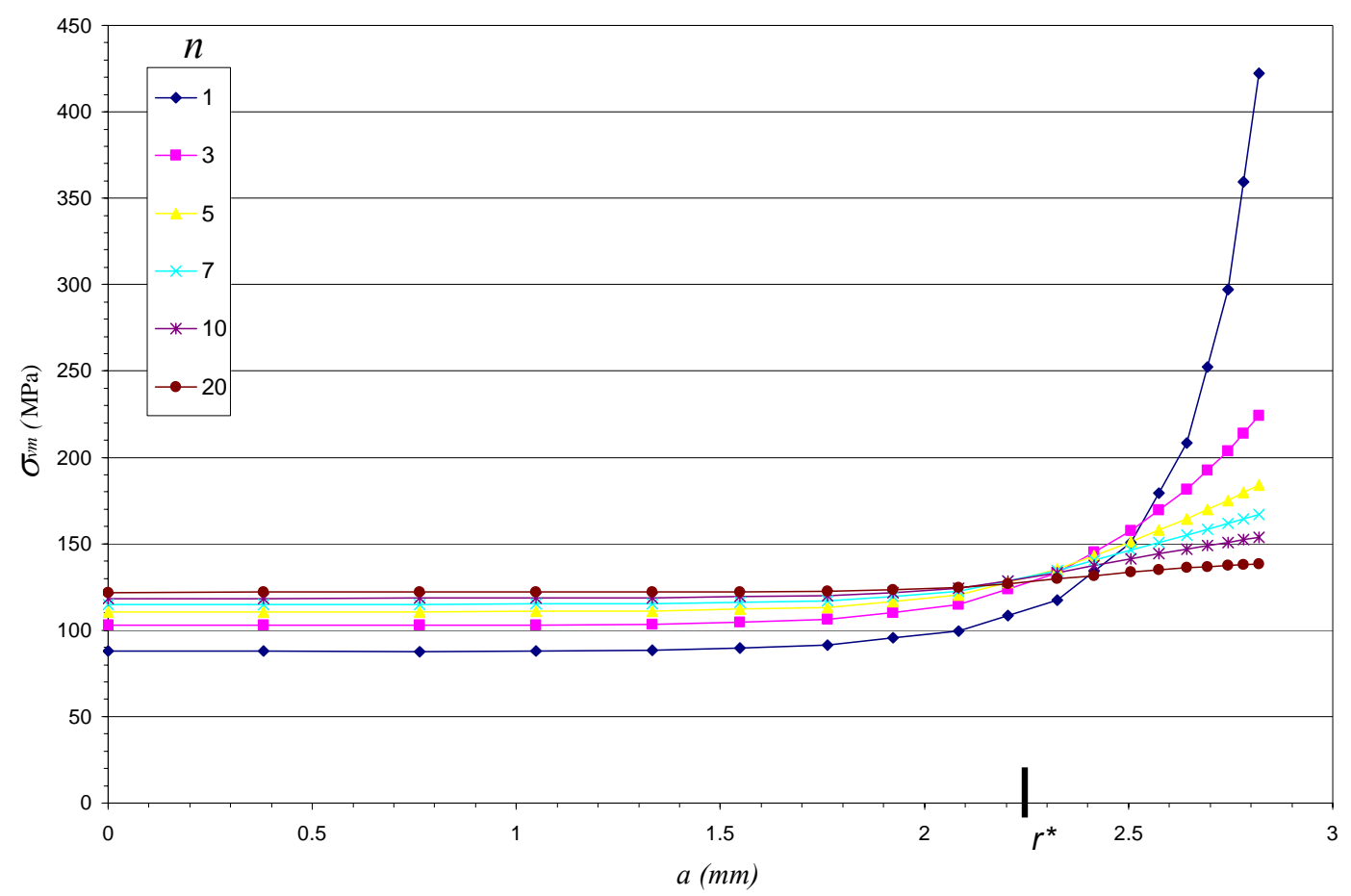

Figure 3: Von-Mises stress distribution across the notch throat for various creep indices $n$ for $d_{n o} / 2 r_{n o}=5, d_{n o}=4.84 \mathrm{~mm}, \sigma_{n e t}=200 \mathrm{MPa} . r^{*}$ is the skeletal point radius for the notch throat. 


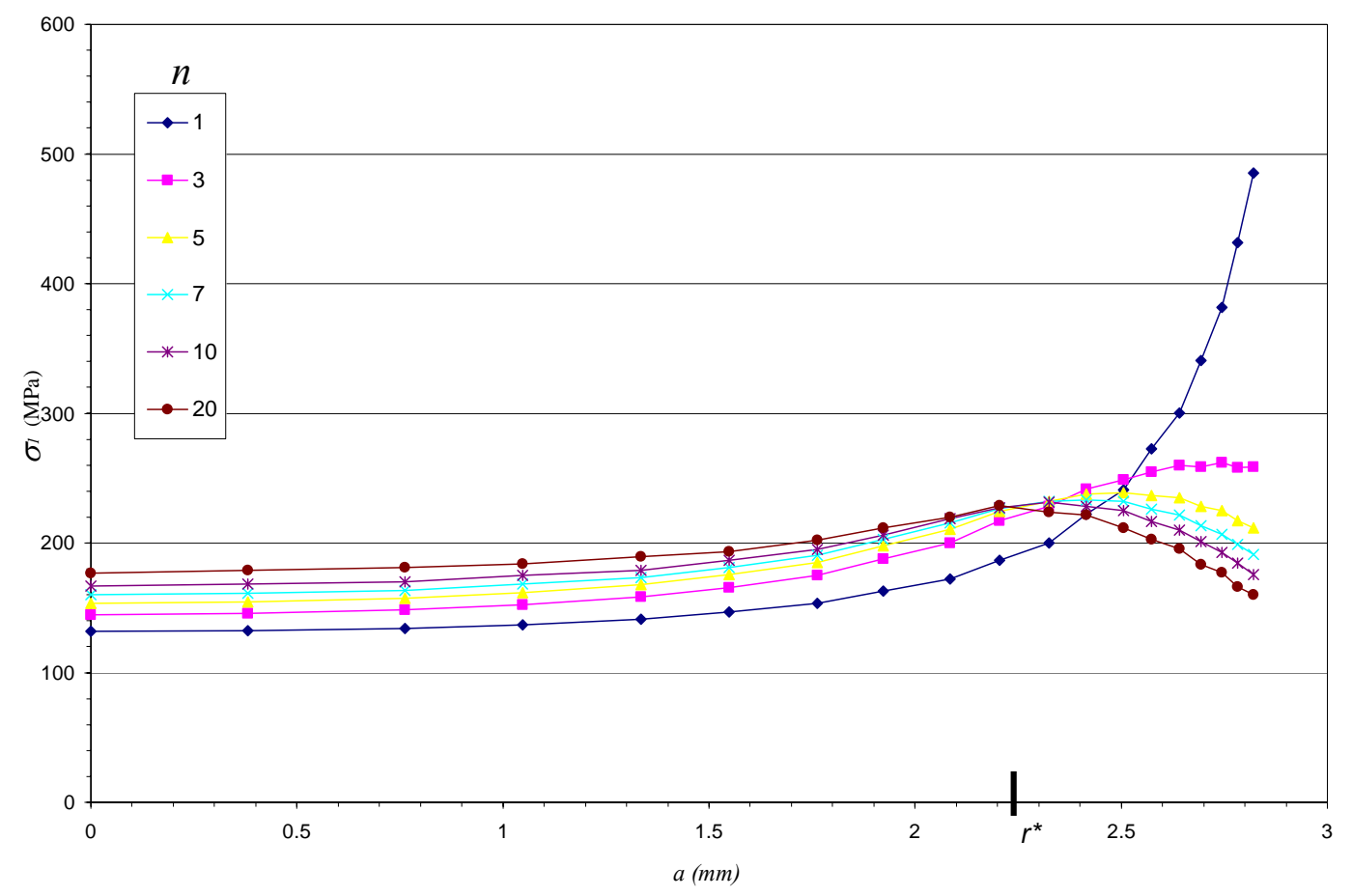

Figure 4: Principal stress distribution across the notch throat for various creep indices $n$ for $d_{n o} / 2 r_{n o}=5, d_{n o}=4.84 \mathrm{~mm}, \sigma_{n e t}=200 \mathrm{MPa} . r^{*}$ is the skeletal point radius for the notch throat.

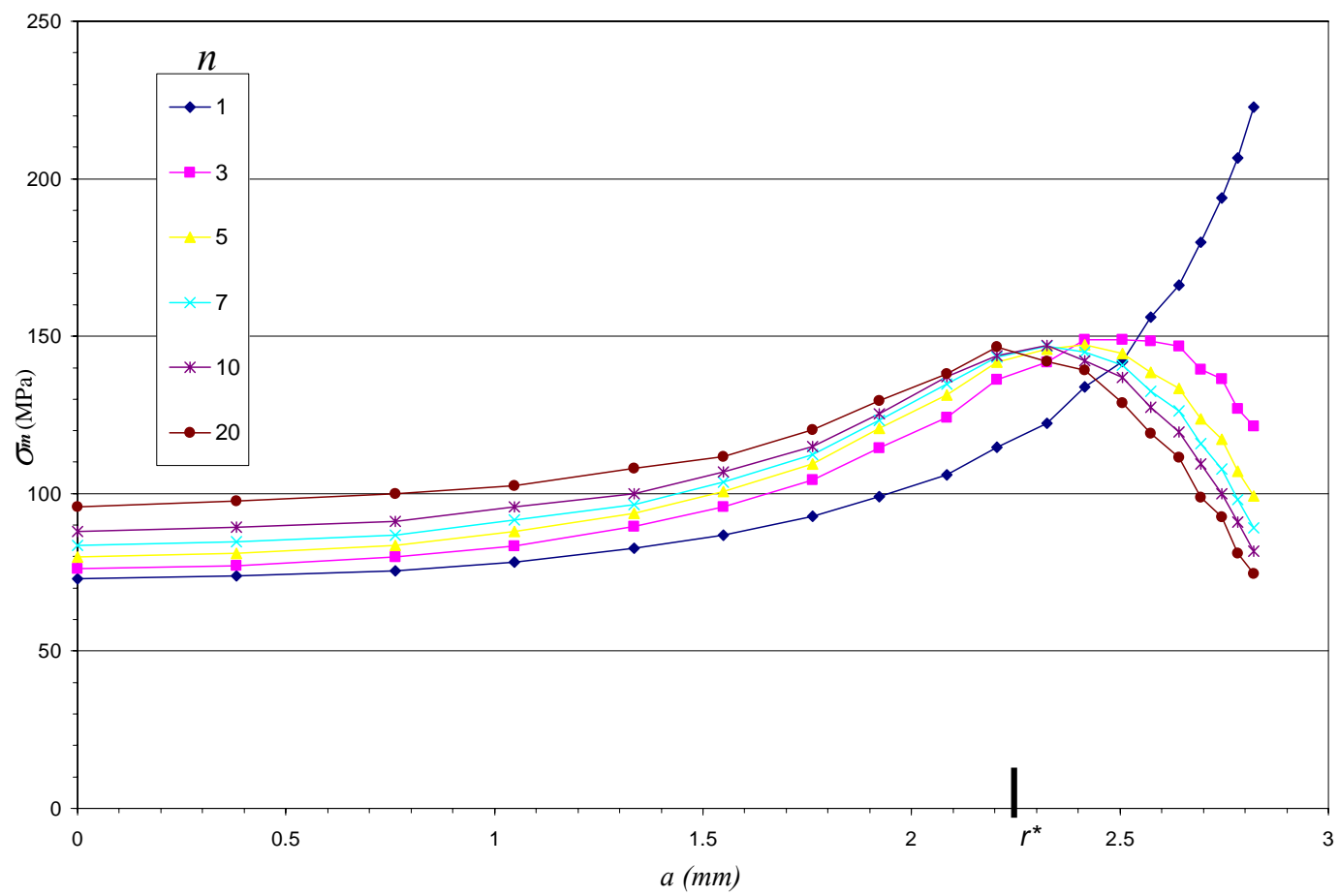

Figure 5: Hydrostatic stress distribution across the notch throat for various creep indices $n$ for $d_{n o} / 2 r_{n o}=5, d_{n o}=4.84 \mathrm{~mm}, \sigma_{n e t}=200 \mathrm{MPa} . r^{*}$ is the skeletal point radius for the notch throat. 


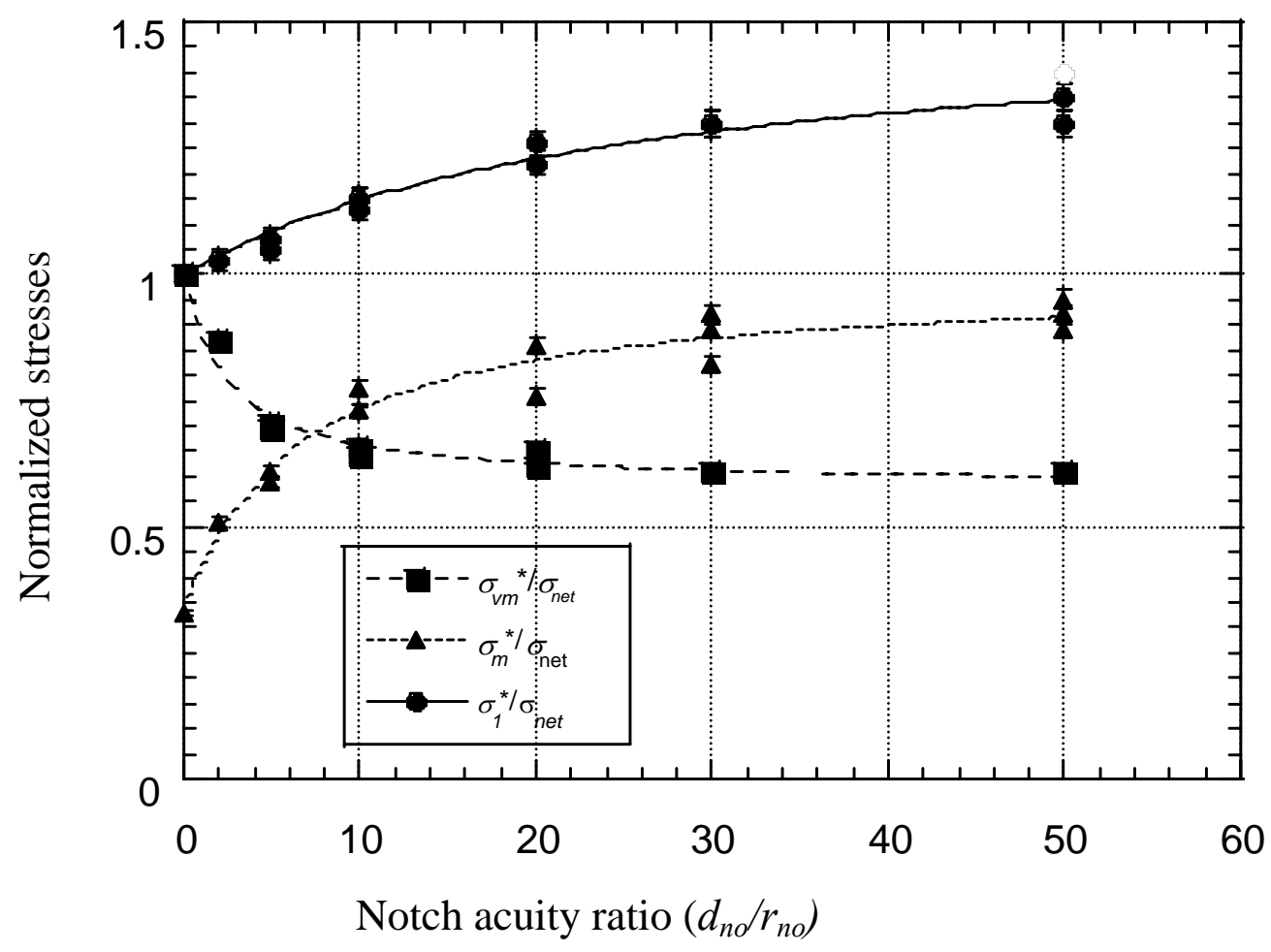

Figure 6: Ratios of skeletal point stresses normalized with respect to net-section stress for a range of notch acuity ratios

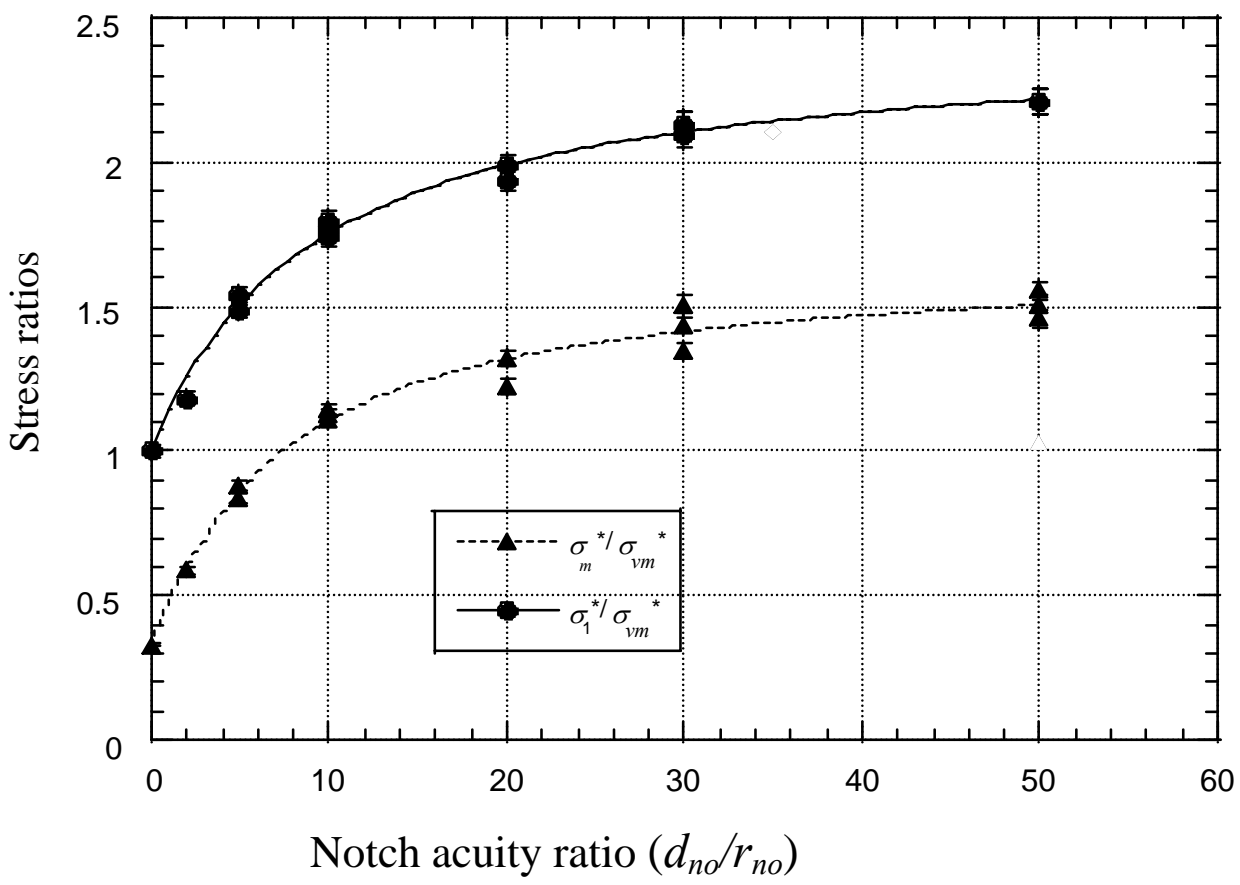

Figure 7: Ratios of skeletal point stresses normalized with respect to Von -Mises skeletal stress for a range of notch acuity ratios 


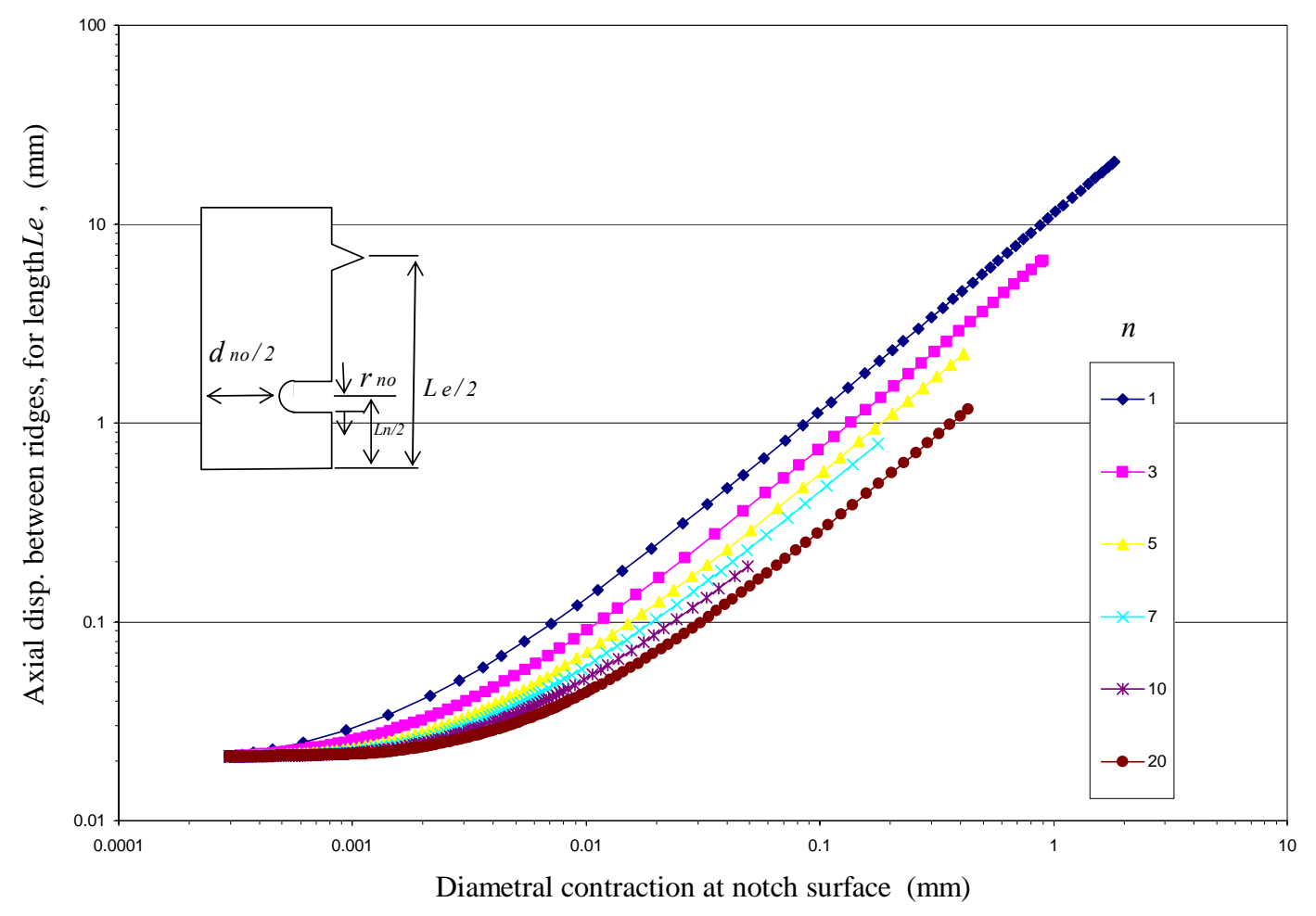

Figure 8: Axial displacement versus diametral contraction for a notched bar with $d_{n o} / 2 r_{n o}=5$, $d_{n o}=4.84 \mathrm{~mm}, L_{n}=12 \mathrm{~mm}$ and $L_{e}=36 \mathrm{~mm}$.

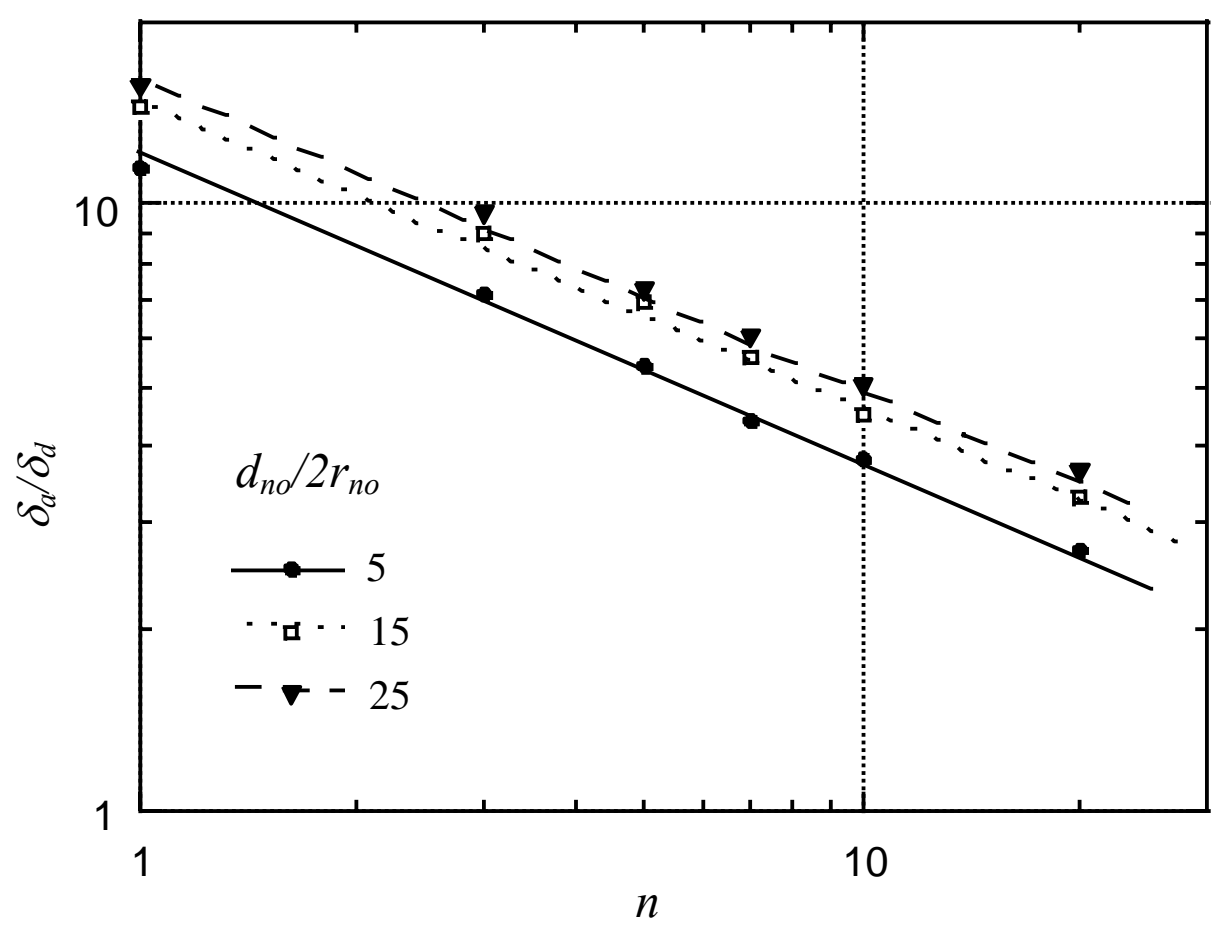

Figure 9: Dependence of axial extension, $\delta_{a}$, to diameter change, $\delta_{d}$, ratio on $n$ for $d_{n o} / 2 r_{n o}=5$, 15 , and 25 